\title{
TUNISIAN MOTHERS' PERCEPTION OF THEIR YOUNG CHILDREN'S INTERACTIVE SCREEN TIME AT HOME
}

\author{
Amel Meziane-Fourati \\ amel_miziane@yahoo.com \\ Essex University, United Kingdom
}

\begin{abstract}
Nowadays, handheld digital tools such as tablets and smartphones are an integral part of a substantial number of households and their compelling nature lure youngsters. Indeed, their user-friendly design together with the wide range of accessible games, educational applications, and videos make them very popular among children as young as two (Lunch and Redpath, 2014). Therefore, it is an undeniable fact that digital use in the home environment can shape pre-school learning experiences and develop emergent numeracy and literacy skills including numbers knowledge, alphabet knowledge, print and phonological awareness (Kucirkova et al., 2013). However, several researchers, health experts, early childhood practitioners and parents have voiced their doubts and concerns about the suitability of using these tools as instructional aids during the early learning phase. Their scepticism is legitimate if one considers possible risks such as increased distractibility, social isolation and exposure to inappropriate content (House, 2012; Miller, 2005; Radesky et al., 2015). In contrast, others have highly approved of these new devices and claim that they can offer multiple opportunities for independent learning, collaboration, creativity and experimentation (Bandura, 2001). Whether digital handheld tools are beneficial or detrimental to children's learning and development remains an on-going debate. Based on the responses of 52 Tunisian working mothers to a self-designed questionnaire and a semi-structured interview, this study aims at investigating various aspects related to Tunisian young children's (aged 18 months to 5 years-old) use of smartphones and tablets at home including: frequency of exposure, reasons for use, mothers' attitudes towards their children's interactive screen time at home, the opportunities they feel these tools offer and the risks they associate with such powerful digital media.
\end{abstract}

Keywords: handheld digital tools, smartphone, tablet, young children - learning, emergent literacy skills, emergent numeracy skills, home environment

\section{INTRODUCTION}

Since the creation of the first home computer and the introduction of Internet to households, the world has witnessed a new technological revolution. As a result, our understanding and perception of the environment surrounding us have been heavily shaped by technology use. During the last two decades, various digital devices have become an integral part of children's lives (Plowman et al., 2010; Wohlwend, 2010), so much so that the expression Digital Natives (Prensky, 2001) was coined to refer to the first generation of children raised in western societies and exposed to omnipresent digital media. These children are fluent in the digital language of computers, video games, and Internet (Underwood and Farrington-Flint, 2015). The pervasiveness of digital media inside and outside households has also generated contemporary sociocultural conceptualizations of the term literacy, and some studies have been using the expression digital literacy to refer not only to reading and writing skills in non-digital contexts but also to skills related to using digital media, where meanings are often multimodal i.e. 
expressed through a combination of spoken and written language, icons, images, sounds as well as animations (Flewitt, 2013).

It goes without saying that one cannot make broad generalisations and assume that all children in different parts of the world are totally immersed in technology at a very young age. As a matter of fact, there still is a noticeable difference between young children's access to digital media in developed nations and developing ones, and a family's socio-economic status has an impact on digital tool ownership and Internet access in most African countries. Tunisia, for example, is a country, which suffers from a digital divide (Norris, 2001) since access to different technologies remains very limited in some parts of the country. As a result, some children develop excellent digital skills, whilst others have little or no opportunity to engage with new media inside or outside home (Wolfe and Flewitt, 2010). In addition, the interconnectedness between socio-cultural norms, family socio-economic features and a child's characteristics plays a crucial role in understanding media-based experiences and produces diverse learning, social as well as behavioural outcomes (Drotner and Livingston, 2008; Oakes, 2009 and Lemish, 2008). For the purpose of the present study, only families that own smartphones and/or tablets have been selected to gain a clearer understanding of how some young Tunisian children harness these media at home.

Handheld digital technologies such as smartphones and tablets, among all types of digital tools have been growing in popularity. Their appealing and user-friendly design makes them hard not to be liked especially when the user in question is a young child (Lunch and Redpath, 2014). Unlike home computers, these devices offer a gestural and interactive interface that corresponds to the characteristics of active engagement coupled with developmentally appropriate fine motor controls (Siegle, 2013). In addition, they represent a digital playground that offers a wide range of educational applications, games and videos. However, the existing body of research on young children use of handheld technology has shown mixed views and so far claims about the effects of smartphones and tablets on early literacy, children's behaviour, and family dynamics have been contradictory (Neumann and Neumann, 2014).

\section{Advantages and disadvantages of early immersion on handheld digital technology}

The accessible learning input offered by interactive screen media comes under the form of intentional learning activities namely applications which are designed for educational purposes but most commonly under the form of material that may trigger incidental learning. With regards to the latter, children can incidentally learn while watching online videos, playing games, listening to songs and chatting while observing adults and other children manipulate a device. This interactive screen time can develop emergent literacy skills including alphabet knowledge, print awareness and phonological awareness, expand world knowledge as well as offer opportunities for experimentation (Bandura, 2001; Kucirkova et al., 2013; Neumann and Neumann, 2014). In a recent study, Kucirkova et al. (2014) found out that learn-to-read applications can help young users practice letters, phonics and enable them to retain new words. Thus, they enrich vocabulary breadth and develop emergent literacy skills, which are fundamental for future reading and writing abilities (Cohen and Cowen, 2011). Moreover, 
digital use combined with social interaction with peers, siblings or parents has been highly recommended as it contributes to language development and fosters social collaboration, which is usually needed to successfully integrate learning communities. Radesky et al. (2015), for instance, called for joint engagement during interactive screen time and maintain that parentchild communication is more likely to promote learning than the Hi-tech artifice of the tool itself. In another recent study carried out by Flewitt et al. (2014), interviews with practitioners from a nursery, a primary school, and a school for young learners with special needs revealed that some participants think that iPads can create promising opportunities for effective independent learning. In other words, the novelty of the applications chosen by practitioners motivate children to learn on their own and actively engage with the task at hand, thus heightening their attention span, which is indispensable for memory retention. Finally, Plowman et al. (2012) brought another advantage into light and maintained that children's interactive screen time not only equips them with operational skills but raises also their awareness about the role of digital technology in daily life. Both of these dimensions are prerequisites to grow up in today's world being a millennial and to ensure effective learning in the $21^{\text {st }}$ century as digital literacy has become crucial.

Taken together, the aforementioned studies promote the educational as well as the social value of contemporary artefacts like smartphones and tablets, but other studies state that the hazards outweigh the benefits. Indeed, enhancements generally used in educational applications and games, such as sound effects and animations can distract young children from the educational content and the learning process itself (Radesky and al., 2015). In addition, when it comes to developing young children's empathy and self-regulation, handheld digital devices remain ill-suited. On other occasions, some studies demonstrate that parents were worried that early exposure to touch-screen devices can result into a disinterest in traditional non-digital activities particularly reading print material (Kucrikova and Littleton, 2016, Ebbeck et al., 2016).

Naturally, early childhood experts, practitioners and parents cannot constantly blame these devices for being a threat to children as adults' irresponsibility itself is the root of a list of serious problems strongly associated with early access to technology. Nowadays, it is common practice among parents to use a smartphone or a tablet in order to occupy their children during daily routines such as eating, shopping, and carrying out domestic chores. This unsupervised access itself may result into increased distractibility, social alienation, and impulsivity (House, 2012; Miller, 2015; Palmer, 2006). Likewise, paediatricians explained that the use of interactive screen media as a behavioural regulation tool is likely to negatively affect children's communicative skills and be detrimental to future social and emotional outcomes (Jenny et al., 2014; Radesky et al., 2015).

\section{Justification and aims of the study}

In the recent society, the ubiquitousness of handheld digital media in a substantial number of households has had an impact on the way young children play, learn and interact. The body of research that exists so far has focused on the use of such artefacts as instructional vehicles in 
formal teaching settings but has disregarded to a great extend the importance of home as the first informal learning environment. Due to the paucity of research on young children's use of handheld digital technologies at home in the MENA region and more specifically in Tunisia, this study comes as an attempt to investigate different relevant areas and answer the following five research questions:

RQ1 How many smartphones and tablets do families who are involved in this study own?

RQ2 How frequently do young children use digital handheld media?

RQ3 Why do young children use digital handheld media?

RQ4 What are mothers' attitudes towards the potential of handheld digital media in developing early literacy, numeracy and creativity? What do they think of using tablets in preschools?

RQ5 What are the benefits and hazards these mothers associate with early immersion in handheld digital technology?

\section{METHODOLOGY}

\section{IV.1. Participants}

52 Tunisian working mothers in their thirties (age range varied from 30 to 39, mean age $=$ 33) participated in this study to report on their children's use of handheld digital tools and express their attitudes and opinions. The gender of participants was not chosen on purpose but was a mere coincidence. $88.5 \%$ of the respondents worked in the Tunisian educational sector as university language teachers at ISEAHZ (The Higher Institute of Applied Studies in Humanities of Zaghouan, University of Tunis) (65.4\%) or as pre-school teachers at l'Etoile kindergarten, which is located in the outskirts of Tunis $(23.1 \%)$. Their children were between the ages of eighteen months and five but most of them were 3-to 4- year old (57.7\%). Their gender was considered irrelevant to the study's main objectives.

\section{IV.2. Research instruments}

Obviously, children at an early age are incapable of reporting on their digital routines. Therefore, a questionnaire was designed to gather data from their mothers. The administered version was written in French (L2) to avoid comprehension problems. The question forms used were yes-no, multiple choice, Lickert-scale and open-ended questions. The last were meant to give participants the freedom to express themselves. Upon completion of filling up the questionnaire, short semi-structured interviews were conducted with all participants to clarify some ambiguous answers and complement others. Data was analysed using SPSS and yielded the results discussed in the next section of the paper.

\section{RESULTS}

Results are presented below under four different headings: 1) home ownership of handheld digital media (in response to RQ1) 2) frequency of young children's interactive screen time 
and different uses at home (in response to RQ2 and RQ3) 3) attitudes towards the potential effects of handheld digital media on a child learning (in response to RQ4), and finally 4) the advantages and drawbacks associated with interactive screen time at a young age (In response to RQ5).

\section{V.1. Home ownership of handheld digital media}

A significant majority of the participants (88.5\%) revealed they had at least one (26.9\%), two $(57.7 \%)$ and even three (3.8\%) smartphones at home. Slightly fewer participants $(80.8 \%)$ own one tablet $(73.1 \%)$ or two $(7.7 \%)$. Interviews with mothers who do not have a tablet at home (19.2\%) revealed that they strongly believe that such portable digital tool remains impractical due to its size and is still a little luxury whereas owning a smartphone is obviously essential for an infinite number of reasons. As for the small minority who do not possess a smartphone, they confessed that the device broke down and was replaced by a basic cell phone for financial motives.

\section{2. Frequency of young children's interactive screen time and different uses at home}

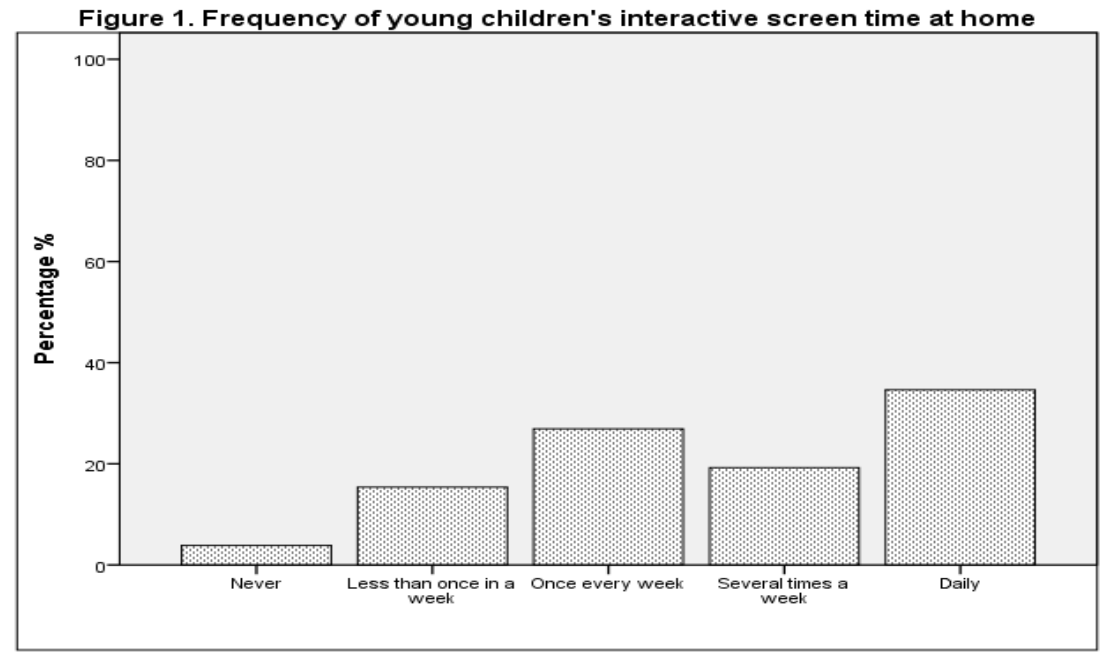

As illustrated in figure 1, 34.6\% of the study sample described their children use of handheld digital media as a daily routine. Interviews with mothers showed that the minimum time duration permitted is of one hour per day and can reach two hours or more during the weekends. Only $26.9 \%$ let their children use a smartphone and/or a tablet once per week and $15.4 \%$ less than once in a week. With respect to the frequency of interactive screen time that children spend without adult supervision, results indicate that almost half the sample i.e. $46.2 \%$ of mothers never let their children use a smartphone and/or a tablet without the presence of an adult whereas $46.2 \%$ confess that they leave them sometimes unsupervised. Surprisingly, interviews with those mothers who opted for "never" (as an alternative to measure their children unsupervised use) revealed that they were in the same room as their child to have a look at what he/she was doing but did not really participate in the digital activity or 
communicate with him/her. One mother, for instance, was cautious because her daughter was often on Youtube to watch cartoons or listen to music. To avoid likely exposure to videos containing foul language or adult content, she didn't leave the room and kept an eye on what her daughter was doing but there a lack of communication.

Although children engaged in various digital activities at home, results demonstrate that their favourite activity remains watching cartoons (26.5\%). In this regard, it seems that handheld digital media sometimes acts as a substitute for television and might be favoured because of the substantial collection of videos it offers on demand. Educational applications are ranked number two (20.3\%) and are closely followed by gaming applications (19\%) and listening to music (16.5\%). The last pastime often involves watching video clips on Youtube too. Finally, taking pictures $(12.7 \%)$ and using Facebook $(2,5 \%)$ were the least favoured activities. It is essential to mention at this point of the analysis that four mothers $(2,5 \%)$ were unable to commentate on their children's digital time as these were usually busy doing household chores. Further classification of the aforementioned uses into digital teaching activities (educational applications) and digital entertaining activities (watching cartoons, listening to songs, taking photos, using Facebook and playing with gaming or educational applications) shows beyond doubt that young children in this study preferred to use smartphones and tablets for entertaining purposes $(77.2 \%)$ much more than for educational purposes $(20.3 \%)$.

\section{3. Attitudes towards the potential effects of handheld digital media on a child learning}

As shown in table 1, most mothers are convinced that handheld digital media can stimulate young children, thus can enhance their creative skills. However, it is evident that fewer mothers believe in the potential of such devices in developing emergent literacy and numeracy skills. In point of fact, answers to Lickert-scale questions showed that $53.8 \%$ of the study sample opted for option "agree" whereas 30.8\% chose option "strongly agree" to describe their positive attitudes towards the effects of handheld digital media on young children's creative development. With respect to emergent literacy skills, participants expressed mixed attitudes (46.2\% had negative attitudes and $42.3 \%$ had positive attitudes, see table 1) towards the impact of interactive screen media on their children's reading development. Additionally, the majority $(57.7 \%)$ rejected the idea that a smartphone or a tablet can enhance emergent writing skills. When interviewed, some mothers explained that a child needs a pen to learn how to write and not a touch-screen interface. Similarly, findings show that mothers expressed differing views about the role that handheld digital media can play in developing or sharpening numeracy skills. 
Table 1 Attitudes towards the potential effects of digital handheld media on a child's learning

\begin{tabular}{|cccccc|}
\hline & $\begin{array}{c}\text { Strongly } \\
\text { disagree }\end{array}$ & Disagree & Neutral & Agree & $\begin{array}{c}\text { Strongly } \\
\text { agree }\end{array}$ \\
Reading & $15.4 \%$ & $30.8 \%$ & $11.5 \%$ & $38.5 \%$ & $3.8 \%$ \\
Writing & $11.5 \%$ & $57.7 \%$ & $7.7 \%$ & $23.1 \%$ & $0 \%$ \\
Numeracy & $7.7 \%$ & $26.9 \%$ & $26.9 \%$ & $38.5 \%$ & $0 \%$ \\
Creativity & $7.7 \%$ & $7.7 \%$ & $0 \%$ & $53.8 \%$ & $30.8 \%$ \\
$\begin{array}{c}\text { Introducing } \\
\text { tablets to pre- }\end{array}$ & $19.2 \%$ & $15.4 \%$ & $11.5 \%$ & $34.6 \%$ & $19.2 \%$ \\
schools & & & & & \\
\hline
\end{tabular}

In spite of the total disbelief that several mothers expressed concerning the ability of handheld digital devices to enhance emergent literacy particularly writing and to a lesser extent numeracy and reading skills, more than half (53.8\%) were in favour of introducing tablets to pre-schools. Further enquiries during interviews showed that they tend to consider a tablet as a digital playground that can re-invent play time and offer innovative entertainment. One mother explained that young children should be exposed to tablets at an early age because they live in a digitalized world, thus need to acquire digital skills. It is also worth mentioning that in none of the recorded interviews did a participant spontaneously suggest that a digital tool could be employed to develop emergent literacy or numeracy skills.

\section{4. The advantages and drawbacks associated with interactive screen time at a young age}

Two open-ended questions asked participants about the advantages and drawbacks of early immersion into digital technology. Although the researcher deliberately added these questions to generate a breadth of responses, many participants failed to provide an answer especially when asked to name some potential advantages. The gathered comments were than analysed and classified into separate categories. The collected data yielded a categorization made of as many advantages as drawbacks (seven per category), but quantitative results revealed that mothers were able to cite drawbacks (61.2\%) more often than advantages (38.8\%). When it comes to the range of potential advantages of early digital access, percentages, as shown in table 2, reflect seriously divergent views and are not in total concordance with results reported in section V.3. Except for digital skills development, which unexpectedly leads a very tight race (19\%), most of the advantages were cited with a similar frequency. The least cited advantage was increase of the concentration span $(9.5 \%)$.

Most mothers interestingly drew an analogy between handheld digital media and television when exposing the hazards of early immersion into digital technology. The most cited drawbacks were cognitive laziness (21.2\%) and social problems (21.2\%). In fact, some mothers strongly believe that using a smartphone or a tablet at an early age encourages lazy thinking 
and physical inactivity, both of which according to them have been plaguing the Tunisian society due to Turkish soap operas (dubbed in Tunisian Arabic) and poor quality TV shows. As such, children are passively exposed to ready-made images and do not really need to use their imagination and/or put their creativity into practice. One specific mother said: "we are poisoning our children's brains" and concluded that "it is no wonder why there are so many youngsters who suffer from learning disabilities". With regards to social problems, mothers brought up the risk that digital tools could easily weaken or put an end to strong family ties, hence lead to social alienation and signs of a violent behaviour (12.1\%). Surprisingly, there was little mention of the negative impact that digital handheld technologies might have on leisure reading.

Table 2 List of advantages and drawbacks associated with early access to digital handheld technology

$\begin{array}{lclc}\text { Advantages } & \text { Percentages } & \text { Drawbacks } & \text { Percentages } \\ \text { Motivation } & 14.3 \% & \text { Mental laziness } & 21.2 \% \\ \text { concentration span } & 9.5 \% & \text { Lack of } & 9.1 \% \\ & & \text { concentration } & \\ \text { Creativity } & 14.3 \% & \text { Social problems } & 21.2 \% \\ \text { Digital awareness } & 19 \% & \text { Violence } & 12.1 \% \\ \text { Entertaining nature } & 14.3 \% & \text { Health hazards } & 18.2 \% \\ \text { World knowledge } & 14.3 \% & \text { Addiction } & 15.2 \% \\ \text { Emergent literacy } & 14.3 \% & \text { Disinterest in } & 3 \% \\ \text { skills } & & \text { reading print } & \\ & & \text { material } & \end{array}$

\section{DISCUSSION AND CONCLUSION}

This study was an attempt to explore some Tunisian young children's interactive screen time using mothers' answers to questionnaires and semi-structured interviews. The quantitative analysis suggests that young children in this study are often attracted to the entertaining nature of interactive tools at the expense of their instructional value. However, due to the small number of participants, the research cannot detect a recurrent or a striking trend in young Tunisian children's digital uses. Obviously, this finding clearly does not imply that occasions of incidental learning are not triggered during these pastimes; however, it is hard to evidence that. Findings also reflect participants' serious doubt about digital media potential in developing early literacy and numeracy skills. Indeed, many mothers believe that handheld digital devices represent the playground of modern time and can be used in pre-schools as recreational gadgets but are far from being teaching tools. Their scepticism was further reiterated when they listed drawbacks more often than advantages. The findings discussed so far parallel to a great extent the conflicting opinions revealed by the existing body of research (see section II). It is also crucial to point out that participants' comments regarding the advantages of early digital use were rather vague. As a matter of fact, more than half of them 
agreed that smartphones and tablets harness and develop children's creativity, but fewer mothers were able to bring up creativity as an advantage in the open-ended question. Of course, such an apparent inconsistency requires further investigation and a larger sample of participants.

Unfortunately, mothers in this study seem to forget that smartphones and tablets are mere artefacts manipulated by humans; therefore, it is their role to shape their children's digital use and choose for them an age appropriate and interesting content that can foster incidental and intentional learning. Another key finding of the study is the lack of parent-child interaction during interactive screen time, which highly reduces the potential of touch-screen devices. Needless to say that handheld digital tools cannot really replace the experiences that young children live in the physical environment surrounding them, but they are here to stay and they have already moulded young children's world understanding, learning and behavioural development. Therefore, it is primarily adults' duty to guide their children in order to make good use of interactive digital tools.

\section{REFERENCES}

Bandura, A. (2001). Social cognitive theory and mass communication. Media Psychology, 3, 265-299

Cohen V. L., Cowen J. E. (2011). Literacy for children in an information age: teaching reading, writing, and thinking. Belmont, CA: Wadsworth Cengage Learning.

Drotner. K., \& Livingston, S. (2008). The international handbook of children, media and culture. London: Sage

Ebbeck, M., Yim, H.Y.B, Chan, Y., \& Goh, M. (2016). Singaporean parents' views of their children's access and use of technological devices. Early Childhood Education Journal, 44(2), 127-134.

Flewitt, R., Messer, D., \& Kucircoka, N. (2014). New directions for early literacy in a digital age: The iPad. Journal of Early Childhood Literacy, O(0), 1-22.

Flewitt, R.S. (2013). Early literacy: A broader vision. TACTYC Occasional Paper 3. Available at: http://tactyc.org.uk/occasional-paper/occasional-paper3.pdf.

House, R. (2012). The inappropriateness of ICT in early childhood education: Arguments from philosophy, pedagogy and developmental psychology. In S. Suggate \& E. Reese (Eds.), Contemporary Debates in Childhood Education and Development (pp. 105-121). New York, NY: Routledge.

Kucirkova, K., \& Littleton, K. (2016). The digital reading habits of children: A national survey of parents' perceptions and practices in relation to children's reading for pleasure with print and digital books. The Open University, BookTrust.

Kucirkova, N., Messer, D., Sheehy, K., \& Fernandez, P. (2014). Children's engagement with educational iPad apps: Insights from a Spanish classroom. Computers and Education, 71, 175-184.

Kucirkova, N., Messer, D., Sheehy, K., \& Flewitt, R.S. (2013). Sharing personalised stories on iPads: A close look at one parent-child interaction. Literacy, 47(3), 115-122.

Lemish, D. (2008). The mediated playground: Media in early childhood. In K. Drotner and S. Levingston (Eds.), The International Handbook of Children, Media, and Culture (pp.152-168). Los Angeles: SAGE

Lynch, J., \& Redpath, T. (2014). 'Smart' technologies in early years literacy education: A meta-narrative of paradigmatic tensions in iPad use in an Australian preparatory classroom. Journal of Early Childhood Literacy, 14(2), 147-174

Miller, E. (2005). Fighting technology for toddlers. Education Digest, 71(3), 55-58.

Neumann, M.M., \& Neumann, D.L. (2014). Touch screen tablets and emergent literacy. Early Childhood Education Journal, 42(4), 231-239.

Norris, P. (2001). Digital Divide: Civic engagement, information poverty, and the Internet worldwide. Cambridge, UK: Cambridge University Press. 
Oakes, J. (2009). The effect of media on children: A methodological assessment from a social epidemiologist. American Behavioral Scientist, 52, 1136-1151.

Palmer, S. (2006). Toxic childhood: How the modern world is damaging our children and what we can do about it. London: Orion.

Plowman L., Stevenson O., Stephen C., \& McPake, J. (2012). Preschool children's learning with technology at home. Computers \& Education, 59(1), 30-37.

Plowman, L., Stephen, C., \& McPake, J. (2010). Growing Up with Technology: Young Children Learning in a Digital World. Abingdon: Routledge.

Prensky, M. (2001). Digital natives, Digital immigrants. On the Horizon, 9(5), 1-6.

Radesky, J.S., Schumacher, J., \& Zuckerman, B. (2015). Mobile and interactive Media use by young children: the good, the bad and the unknown. Paediatrics, 135(1), 1-3

Siegle, D. (2013). iPads: Intuitive Technology for 21st-Century Students. Gifted Child Today, 36(2), 146-150.

Underwood, J.D., \& Farrington-Flint, L. (2015). Learning and the e-generation. Chichester: Wiley-Blackwell.

Wohlwend, K. (2010). A is for Avatar: Young children in literacy 2.0 worlds and literacy 1.0 Schools. Language Arts, 88(2), 144-152.

Wolfe, S., \& Flewitt, R.S. (2010). New technologies, new multimodal literacy practices and young children's metacognitive development. Cambridge Journal of Education, 40(4), 387-399 